\title{
Status of intestinal parasitic infections among residents of Jimma Town, Ethiopia
}

\author{
Ayalew Jejaw ${ }^{1 *}$, Ahmed Zeynudin², Endalew Zemene ${ }^{2}$ and Tariku Belay ${ }^{2}$
}

\begin{abstract}
Background: Intestinal parasites cause considerable morbidity and mortality in the world, especially in developing countries like Ethiopia. Both urban and rural inhabitants are vulnerable to infection with intestinal parasites in developing countries. The aim of this study was to determine the status of intestinal parasitic infections (IPIs) among residents of Jimma Town, seven years after high prevalence was reported.

Results: Four hundred and thirty four residents of Jimma Town were included in this study. By the cross-sectional survey, the overall prevalence of intestinal parasites was 209 (48.2\%). Nine species of intestinal parasites were isolated, Ascaris lumbricoides and Trichuris trichiura being the most predominant. Residence in Hermata Mentina kebele, Adjusted Odds Ratio (AOR), 3.0, 95\% Cl, 1.71-5.39), age less than 10 years (AOR, 3.7, 95\% Cl, 1.33-10.36), illiteracy (AOR, 3.2, 95\% Cl, 1.64-6.19), estimated monthly family income of less than 500 Ethiopian Birr (AOR, 2.9, $95 \% \mathrm{Cl}, 1.32-4.90)$ and irregular washing hands before meal (AOR, 5.3, 95\% Cl, 1.36-21.07) were predictors of IPI in this study. The retrospective study revealed a significant decrease $(P=0.037)$ in the proportion of patients infected with intestinal parasites out of those who requested stool examination over the six-year period.
\end{abstract}

Conclusion: This study confirms that IPIs are still common among residents of Jimma Town. Nearly half of the study participants were infected with at least one intestinal parasite. Public health interventions targeting prevention of IPIs should be strengthened in Jimma Town.

Keywords: Intestinal parasites, Prevalence, Jimma Town, Ethiopia

\section{Background}

Intestinal parasitic infections (IPIs) are among the major health problems in developing countries. Human intestinal parasites, caused by intestinal helminthic and protozoan parasites, result in significant morbidity and mortality in endemic countries. Globally, in 2010, an estimated 819.0 million people were infected with Ascaris lumbricoides, 438.9 million with the hookworms and 464.6 million Trichuris trichiura [1]. These soil transmitted helminthes (STHs) disproportionately affect people in developing countries, where sanitary facilities and clean water supply are scarce. In developed countries, the intestinal protozoan parasites are more common than the STHs [2-5].

Giardiasis, amebiasis, cryptosporidiosis, cyclosporidiosis and isosporiasis are the common parasitic protozoan diseases of significant importance. The microbial agents

\footnotetext{
* Correspondence: ayalewjejaw@yahoo.com

${ }^{1}$ Department of Biomedical Science, College of Health Sciences, Mizan Tepi University, Mizan Teferi, Ethiopia

Full list of author information is available at the end of the article
}

causing these diseases are mainly waterborne [6]. The coccidian parasites Cryptosporidum species, Cyclospora cayetenensis, Isospora belli and Blastocystis hominis are opportunistic intestinal parasites of significant importance in HIV/AIDS patients $[7,8]$.

Intestinal parasites affect people of all age; however, the impact on young children and pregnant women is severe. Polyparasitism and moderate-to-heavy infection with the STHs could be associated with poor growth in children [9-11] and reduced cognitive function [12], which could be reversible after deworming [13]. Association of giardiasis with vitamin A deficiency in school children has been documented [14]. In pregnant women, the STHs increase the risk of anemia $[15,16]$. Hookworm infections result in significant reduction on iron store in pregnant women [17].

Ethiopia is a developing country where IPIs are major public health problems. Previous studies carried out in Ethiopia revealed high prevalence of IPIs $[18,19]$. The burden of intestinal parasites, particularly the STHs, is 
often very high in school children [20,21]. Amoebiasis and giardiasis are also common parasitic diseases in Ethiopia, despite the diagnostic inaccuracy in the routine laboratory diagnosis of amebiasis [22].

At the end of 2004, prevalence of intestinal parasites among residents in Jimma Town was 83\% [23]. The study was a community-based cross-sectional survey, in which six of the 13 kebeles of Jimma Town were included. Since then, interventions by urban health extension workers (UHEWs) aimed at improving sanitary condition of the town, is being carried out. Environmental hygiene and sanitation is one of the four health subprograms of the health extension program (HEP). Thus, the health extension workers provide health information at household level to create awareness and improve skills in dealing with preventable diseases. According to the information obtained from Jimma Town Health Office, the UHEWs are involved in school water, sanitation and hygiene and awareness creation at household level to access health services, among others. As a result of introduction of the program, primary health care coverage of the country has improved [24]. The present study is aimed at determining the status of IPIs among residents of Jimma Town, seven years after $83 \%$ prevalence was documented.

\section{Methods}

\section{Study area}

The study was conducted in Jimma Town, located 350 kms south-west of Addis Ababa. The town is divided into 13 kebeles (smallest governmental administrative units in Ethiopia). The geographical coordinates of the town are approximately $7^{\circ} 41^{\prime} \mathrm{N}$ latitude and $36^{\circ} 50^{\prime} \mathrm{E}$ longitude. The town is located at average altitude of 1,780 meters above sea level. According to the 2007 Central Statistical Agency census report, the projected total population of the town is 134,040 . The town is generally characterized by warm climate with mean annual maximum temperature of $30^{\circ} \mathrm{C}$ and mean annual minimum temperature of $14^{\circ} \mathrm{C}$. The annual rainfall ranges from 1138 to $1690 \mathrm{~mm}$. Four public health centers, two public hospitals and several private clinics are currently found in Jimma Town.

\section{Study design and sampling}

Community-based cross-sectional survey of intestinal parasites was conducted in selected kebeles of Jimma Town from January to March 2012. Moreover, retrospective study of intestinal parasites was carried out by reviewing six-year laboratory records of the public health facilities in Jimma Town. Sample size for the survey was estimated using the single population proportion formula, considering prevalence $(\mathrm{P})$ of $83 \%$ from the previous study [23], 95\% confidence level and 5\% margin of error. This gave us sample size of 217. After multiplying it by two to account for the design effect, the final sample size was calculated to be 434 individuals. The source population for the study was residents of Jimma Town of all ages and both sexes.

A multistage sampling technique was employed. Four of the thirteen kebeles were selected by simple random sampling. Then, the sample size was allocated to the selected kebeles proportional to the total number of households in each kebele. Accordingly, 184, 81, 78 and 91 study participants were allocated to Bocho Bore, Bosa Addis, Seto Semero and Hermata Mentina kebeles, respectively. Households were selected from each of the kebeles by systematic sampling using list of the households as sampling frame. Finally, one individual was randomly selected from each of the selected households and included in the study.

The cross-sectional survey in our study is similar with the previous study done in Jimma [23] with respect to: i) data collection methods, ii) diagnostic methods used (direct saline smear and formol-ether concentration techniques), ii) profile of study participants included (residents of Jimma Town of all ages and both sexes). However, our study involved smaller number of study participants and kebeles compared to the previous study.

\section{Data collection and laboratory processing}

Socio-demographic profile and data on risk factors associated with IPI were gathered by house-to-house interview using pre-tested questionnaire. Trained UHEWs who were conversant of the local languages (Amharic and Afan Oromo) interviewed the study participants. The questionnaire was first developed in English and then translated to Afan Oromo and Amharic by native speakers of the languages. In addition to the questionnaire data, single stool specimen was collected from each of the study participants and processed. The stool specimens were examined using direct saline smear and formol-ether concentration methods [25]. The direct saline smears were examined immediately at the nearby kebeles and health centers, while portion of the specimens was preserved with $10 \%$ formaline and transported to Jimma University Medical Parasitology laboratory for formol-ether concentration. Experienced laboratory technologists processed and examined the specimens.

Besides the cross-sectional survey, six-year laboratory records of intestinal parasites in the public health facilities were reviewed retrospectively. Data of patients who sought stool examination in the health care centers during the six years were extracted. The extracted data include: 1) date of stool examination; 2) total number of patients who requested stool examination 3) result of the stool examination and 4) species of intestinal parasites isolated. In Ethiopia, majority of the public health facilities do the direct wet mount as a routine laboratory diagnosis of IPIs. 


\section{Data analysis}

Data were entered, cleaned and analyzed using SPSS version 16.0 software package. Descriptive statistics were used to summarize demographic profile of the study participants. Bivariate and multivariate analyses were used to assess the association between explanatory variables and the outcome variable. The magnitude of the association was measured using adjusted odds ratio (AOR) and $95 \%$ confidence interval $(\mathrm{CI})$. A P-value $<0.05$ was considered as significant.

\section{Ethical considerations}

Ethical clearance was obtained from Jimma University Research and Ethics Review Committee and permission was obtained from Jimma Zone Health Office. Informed consent was sought from each of the adult study participants and guardians/parents in case of children aged less than 18 years, prior to data collection. Information collected from the study participants was kept confidential. During the survey, individuals found to be infected with intestinal parasites were treated according to the national guideline.

\section{Results}

Socio-demographic characteristics of the study participants A total of 434 study participants had participated in this study. Most of the study participants (64.1\%) were female (Table 1). Age of the study participants ranged from 1 to 79 years with mean age of 25.3 years.

\section{Prevalence of intestinal parasites}

Out of the 434 study participants, 209 (48.2\%) were positive for at least one species of intestinal parasite. A. lumbricoides was the predominant parasite, detected in $120(27.6 \%)$ of the study participants followed by T. trichiura (Figure 1). Entamoeba histolytica/dispar/moshkovskii was the predominant protozoan parasite detected in $24(5.5 \%)$ of the study participants.

One hundred and sixty eight (80\%) and 41 (20\%) of the infected individuals had single and multiple parasite infections, respectively. Multiple infections were detected in $9.5 \%$ of the total study participants. The multiple intestinal parasite infections were mainly due to A. lumbricoides, T. trichiura and E. histolytica/dispar/moshkovskii.

Decline in prevalence of each of the intestinal parasites, except Taenia species which remained the same, was noted in this study compared to the previous study. The STHs T. trichiura, A. lumbricoides and hookworms were predominant in the previous study. In this study, while A. lumbricoides and T. trichiura are still predominant hookworm remarkably decreased from $17.5 \%$ in $2004 / 05$ to $0.7 \%$ in this study (Figure 2).

Factors associated with IPIs were demonstrated in Table 2. Males were slightly more infected than females.
Table 1 Characteristics of the study participants, Jimma Town, Southwest Ethiopia, 2012

\begin{tabular}{|c|c|c|}
\hline Characteristics & & Frequency (\%) \\
\hline \multirow[t]{4}{*}{ Kebele } & Bocho Bore & $184(42.4)$ \\
\hline & Hermata Mentina & $91(20.9)$ \\
\hline & Bossa Addis & $81(18.7)$ \\
\hline & Seto Semero & $78(18.0)$ \\
\hline \multirow[t]{2}{*}{ Gender } & Male & $156(35.9)$ \\
\hline & Female & $278(64.1)$ \\
\hline \multirow[t]{6}{*}{ Occupation } & Private & $44(10.1)$ \\
\hline & Employed & $46(10.6)$ \\
\hline & House wife & $101(23.3)$ \\
\hline & Daily labourer & $40(9.2)$ \\
\hline & Student & $196(45.2)$ \\
\hline & Others & $7(1.6)$ \\
\hline \multirow[t]{5}{*}{ Age group in years } & $\leq 10$ & $93(21.4)$ \\
\hline & $11-20$ & $120(27.6)$ \\
\hline & $21-30$ & $88(20.3)$ \\
\hline & $31-40$ & $65(15.0)$ \\
\hline & $>40$ & $68(15.7)$ \\
\hline \multirow[t]{2}{*}{ Educational status } & Illiterate & $61(14.0)$ \\
\hline & Literate & $373(86.0)$ \\
\hline \multirow[t]{2}{*}{ Latrine availability } & Present & $358(82.3)$ \\
\hline & Absent & $76(17.7)$ \\
\hline \multirow{2}{*}{$\begin{array}{l}\text { Latrine with hand washing } \\
\text { facility }(n=358)\end{array}$} & Yes & $60(16.8)$ \\
\hline & No & $298(83.2)$ \\
\hline
\end{tabular}

After adjusting for possible confounding variables (Table 2), residence in Hermata Mentina kebele (AOR $=3.037,95 \%$ CI: $1.71-5.39)$, age group less than 10 years $(\mathrm{AOR}=3.718$, 95\% CI: 1.33-10.36), illiteracy (AOR $=3.196$, 95\% CI: $1.64-$ 6.19), estimated family income of less than 500 Ethiopian birr $(\mathrm{AOR}=2.875,95 \% \mathrm{CI}: 1.32-4.90)$ and irregular washing of hands before meal $(\mathrm{AOR}=5.355,95 \% \mathrm{CI}$ : 1.36 21.07) were significantly associated with IPIs.

\section{Retrospective record review}

Laboratory records of patients who requested stool examination in the public health institutions during the six years were reviewed retrospectively. Accordingly, the proportion of patients positive for intestinal parasites decreased from $43.34 \%$ in 2006 to $31.83 \%$ in 2011 . During these periods, a total of 69,782 stool specimens had been examined in the health facilities. Overall, $36.22 \%$ of the stool specimens were positive for at least one species of intestinal parasite. The reduction in the proportion of patients positive for intestinal parasites was significant $(\mathrm{P}=0.037)$ (Figure 3$)$. 


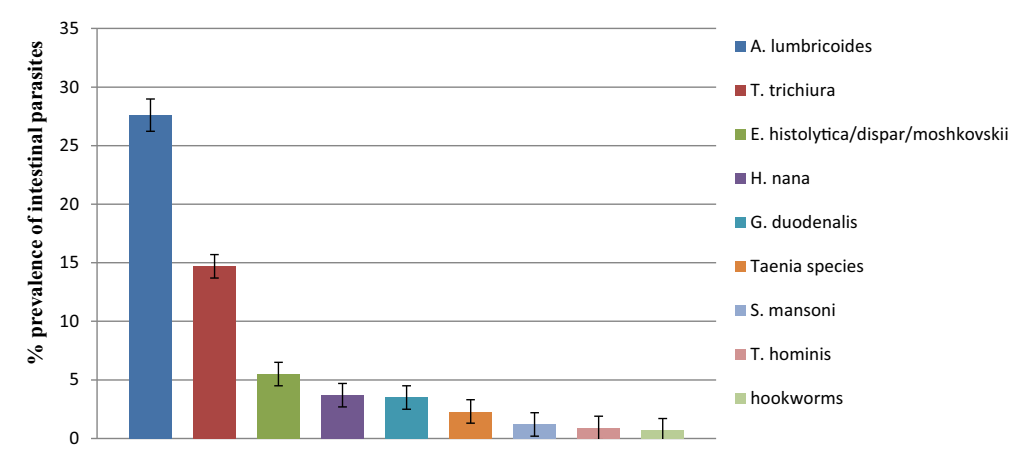

Figure 1 Prevalence and types of intestinal parasites identified among residents in Jimma Town, 2012.

\section{Discussion}

The overall prevalence of intestinal parasites among residents in Jimma Town in this study was $48.2 \%$. The overall prevalence of intestinal parasites declined from $83 \%$ at the end of 2004 [23] to $48.2 \%$ in this study. The marked reduction in the overall prevalence of intestinal parasites could be the outcome of introduction of the HEP. Ethiopian Ministry of Health launched Rural Health Extension Program in 2003 and the Urban Health Extension Program in 2009 [26]. The program has a defined package of basic and essential promotive, preventive and selected high impact curative health services targeting households.

Despite the remarkable reduction in the overall prevalence of intestinal parasites compared to the previous study, nearly half $(48.2 \%)$ of the residents were infected by at least one species of intestinal parasite. This shows that intestinal parasites still pose significant burden to residents of Jimma Town. The finding of this study calls for urgent interventions particularly targeting school-age children, as the prevalence of intestinal parasites is disproportionately higher in this age group. Preventive chemotherapy to school-age children is required as the STHs could result in significant nutritional impact [27] and poor cognitive performance [28].

Our study investigated several possible factors associated with IPIs and identified predicators of infection. Accordingly, illiteracy, low family income and irregular washing of hands before meal were predicators of IPIs in this study. This shows the role of education in preventing IPIs and keeping personal hygiene practices. The significant association of low family income with IPIs may be related to lack of pure water supply and sanitation facilities. Several studies also documented association of IPIs to poor personal hygiene, lack of sanitary facilities and poor economic status $[29,30]$. The prevalence of Taenia species remained the same (2.3\%) in the previous and this study. The dietary habit of consuming raw meat as in kitfo and kurt in Ethiopia in general and Jimma Town in particular likely contributed for this.

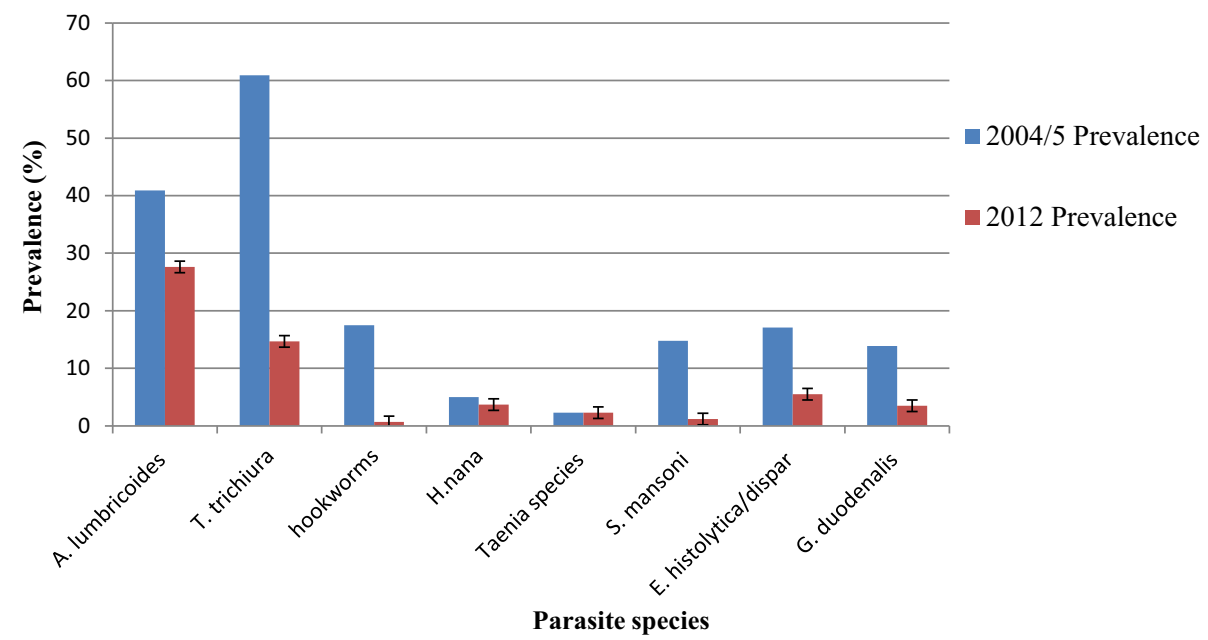

Figure 2 Comparison on prevalence of each of the intestinal parasites in 2004/05 and 2012. 
Table 2 Factors associated with intestinal parasite infection among residents in Jimma Town, Southwest Ethiopia, 2012

\begin{tabular}{|c|c|c|c|c|c|c|}
\hline \multicolumn{2}{|c|}{ Characteristics } & \multicolumn{2}{|c|}{ Intestinal parasite } & \multirow{3}{*}{$\begin{array}{c}\text { COR }(95 \% \mathrm{Cl}) \\
1\end{array}$} & \multicolumn{2}{|c|}{ AOR $(95 \% \mathrm{Cl})$} \\
\hline & & Positive $\mathrm{n}(\%)$ & Negative $n(\%)$ & & & P-value \\
\hline \multirow[t]{4}{*}{ Kebele } & Bocho Bore & $87(47.3)$ & $97(52.7)$ & & 1 & $<0.001$ \\
\hline & Hermata Mentina & $59(64.8)$ & $32(35.2)$ & $2.1(1.22-3.45)^{*}$ & $3.0(1.71-5.39)$ & \\
\hline & Seto Semero & $32(41)$ & $46(59)$ & $0.8(0.45-1.32)$ & $0.8(0.42-1.40)$ & \\
\hline & Bossa Addis & $31(38.3)$ & $50(61.7)$ & $0.7(0.40-1.17)$ & $0.7(0.40-1.33)$ & \\
\hline \multirow[t]{2}{*}{ Sex } & Male & 83(53.2) & 73(46.8) & $1.4(0.92-2.03)$ & $1.5(0.931-2.27)$ & $>0.05$ \\
\hline & Female & $126(45.3)$ & $152(54.7)$ & 1 & 1 & \\
\hline \multirow[t]{5}{*}{ Age group in years } & $<10$ & $60(64.5)$ & $33(35.5)$ & $1.6(0.85-2.82)$ & $3.8(1.33-10.36)$ & $<0.001$ \\
\hline & $10-20$ & $64(53.3)$ & $56(46.7)$ & 1 & 1 & \\
\hline & $21-30$ & $40(45.5)$ & $48(54.5)$ & $0.7(0.42-1.26)$ & $0.8(0.45-1.53)$ & \\
\hline & $31-40$ & $25(38.5)$ & $40(61.5)$ & $0.6(0.29-1.01)$ & $0.6(0.28-1.10)$ & \\
\hline & $>40$ & $20(29.4)$ & 48(70.6) & $0.4(0.19-.68)^{*}$ & $0.3(0.13-.55)$ & \\
\hline \multirow[t]{2}{*}{ Educational status } & Illiterate & $37(60.7)$ & 24(39.3) & $1.8(1.03-3.13)^{*}$ & $3.2(1.64-6.19)$ & $<0.001$ \\
\hline & Literate & $172(46.1)$ & 201(53.9) & 1 & 1 & \\
\hline \multirow[t]{2}{*}{ Monthly family income ${ }^{* *}$} & $<500$ & 155(52.9) & 138(47.1) & $1.5(0.76-2.764)^{*}$ & $2.9(1.32-4.90)$ & 0.041 \\
\hline & $\geq 500$ & $39(37.9)$ & $64(62.1)$ & 1 & 1 & \\
\hline \multirow[t]{2}{*}{ Hand washing before meals } & Always & 196(46.9) & $222(53.1)$ & 1 & 1 & 0.016 \\
\hline & Sometimes & 13(81.3) & $3(18.7)$ & $4.9(1.37-17.47)^{*}$ & $5.4(1.36-21.07)$ & \\
\hline \multirow[t]{3}{*}{ Solid waste disposal method } & Burning & $128(44.9)$ & $157(55.1)$ & 1 & 1 & $>0.05$ \\
\hline & Pit & $67(54.9)$ & $55(45.1)$ & $1.5(0.976-2.288)$ & $1.3(0.809-2.114)$ & \\
\hline & Open field & 14(51.9) & $13(48.1)$ & $1.3(0.599-2.911)$ & $1.4(0.568-3.293)$ & \\
\hline
\end{tabular}

*Statistically significant at $\mathrm{P}<0.05, \mathrm{COR}=$ Crude Odds Ratio, $\mathrm{AOR}=$ Adjusted Odds Ratio, adjusted for other factors shown in the table, $\mathrm{Cl}=\mathrm{Confidence} \mathrm{Interval}$ **Estimated monthly family income in Ethiopian Birr.

The following limitations of our study should be considered when interpreting the results. Intensity of the STHs has not been determined. As a result, severity of STH infections could not be shown. Moreover, the prevalence data generated by the retrospective study represents data of patients who sought stool examination at the health facilities, thus, it could not be generalized to the general population.

\section{Conclusion}

There was a significant decrease in overall prevalence of intestinal parasites over the six-year period. However,

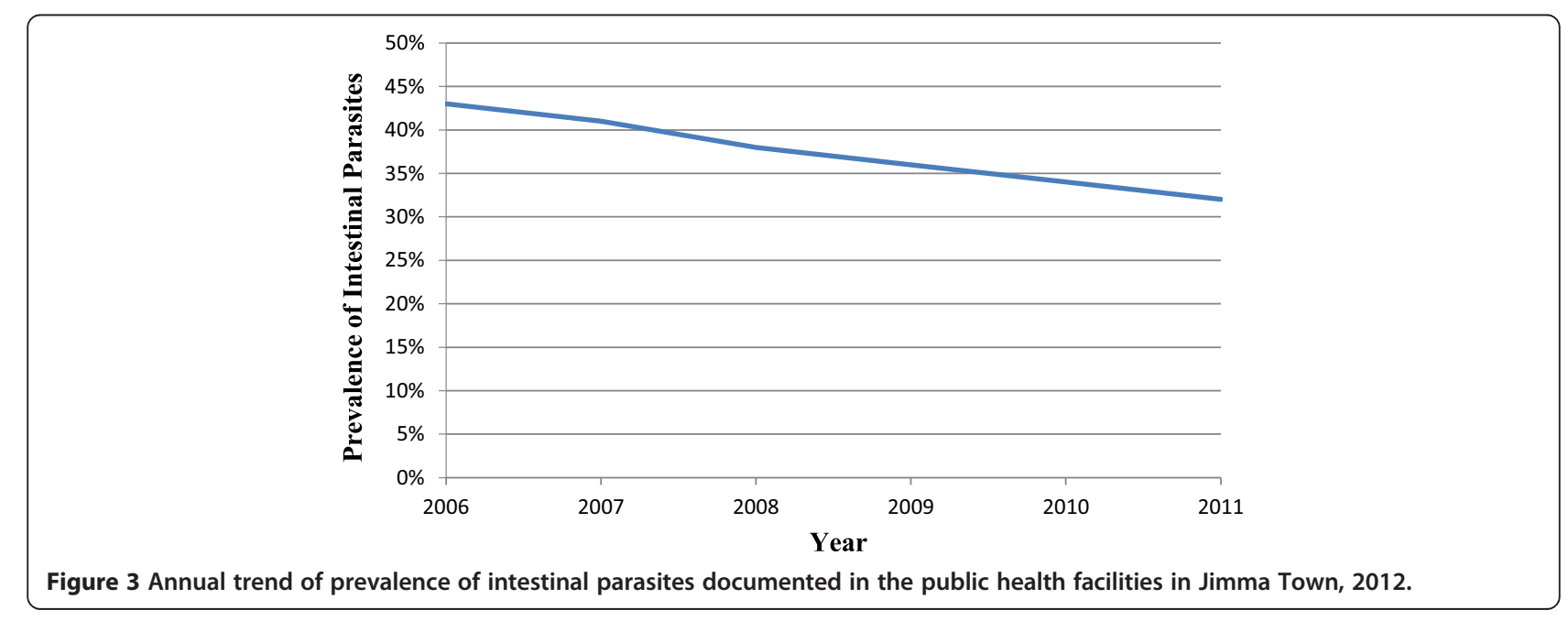


nearly half of the study participants harbored at least one species of intestinal parasite, A. lumbricoides and T. trichiura being the most predominant. Control efforts should focus on provision of health information to improve personal hygiene practices and properly dispose human excreta. School-based awareness creation on the modes of transmission of intestinal parasites is recommended.

\section{Competing interests}

The authors declare that they have no competing interests.

\section{Authors' contribution}

AJ and TB conceived and designed the study; AJ, TB and AZ analysed the data; EZ involved in data acquisition and drafted the manuscript; AZ reviewed the manuscript. All authors read and approved the manuscript.

\section{Acknowledgments}

We are grateful to Jimma University for the financial support. We acknowledge Jimma Town Health Office, kebele leaders and the health extension workers for facilitating the data collection. We thank the study participants for participating in this study.

\section{Author details}

'Department of Biomedical Science, College of Health Sciences, Mizan Tepi University, Mizan Teferi, Ethiopia. ${ }^{2}$ Department of Medical Laboratory Sciences and Pathology, College of Public Health and Medical Sciences, Jimma University, Jimma, Ethiopia.

Received: 13 April 2014 Accepted: 31 July 2014

Published: 7 August 2014

\section{References}

1. Pullan RL, Smith JL, Jasrasaria R, Brooker SJ: Global numbers of infection and disease burden of soil transmitted helminth infections in 2010 . Parasit Vectors 2014, 7:37. doi:10.1186/1756-3305-7-37.

2. Silvestri C, Greganti G, Arzeni D, Morciano A, Castelli P, Barchiesi F, Cirioni O, Giacometti A: Intestinal parasitosis: data analysis 2006-2011 in a teaching hospital of Ancona, Italy. Infez Med 2013, 21:34-9.

3. Daly ER, Roy SJ, Blaney DD, Manning JS, Hill VR, Xiao L, Stull JW: Outbreak of giardiasis associated with a community drinking-water source. Epidemiol Infect 2010, 138:491. doi:10.1017/S0950268809990744.

4. Sagebiel D, Weitzel T, Stark K, Leitmeyer K: Giardiasis in kindergartens: prevalence study in Berlin, Germany, 2006. Parasitol Res 2009, 105:681-687. doi:10.1007/s00436-009-1438-5.

5. Ten Hove R, Schuurman T, Kooistra M, Möller L, van Lieshout L, Verweij Jj: Detection of diarrhoea-causing protozoa in general practice patients in The Netherlands by multiplex real-time PCR. Clin Microbiol Infect 2007, 13:1001-1007. doi:10.1111/j.1469-0691.2007.01788.x.

6. Leclerc H, Schwartzbrod L, Dei-Cas E: Microbial agents associated with waterborne diseases. Crit Rev Microbiol 2002, 28:371-409.

7. Mariam ZT, Abebe G, Mulu A: Opportunistic and other intestinal parasitic infections in AIDS patients, HIV seropositive healthy carriers and HIV seronegative individuals in southwest Ethiopia. East Afr J Public Health 2008, 5:169-73.

8. Alemu A, Shiferaw Y, Getnet G, Yalew A, Addis Z: Opportunistic and other intestinal parasites among HIV/AIDS patients attending Gambi higher clinic in Bahir Dar city, North West Ethiopia. Asian Pac J Trop Med 2011, 4:661-5. doi:10.1016/S1995-7645(11)60168-5.

9. Sanchez AL, Gabrie JA, Usuanlele MT, Rueda MM, Canales M, Gyorkos TW: Soil-transmitted helminth infections and nutritional status in school-age children from rural communities in Honduras. PLOS Negl Trop Dis 2013, 7:e2378. doi:10.1371/journal.pntd.0002378.

10. Wang XB, Wang GF, Zhang LX, Luo RF, Wang JJ, Medina A, Eggleston K, Rozelle S, Smith S: Correlation between soil-transmitted nematode infections and children's growth. Zhongguo Xue Xi Chong Bing Fang Zhi Za Zhi 2013, 25:268-74.

11. Shang Y, Tang LH, Zhou SS, Chen YD, Yang YC, Lin SX: Stunting and soil-transmitted-helminth infections among school-age pupils in rural areas of southern China. Parasit Vectors 2010, 3:97. doi:10.1186/1756-3305-3-97.
12. Ezeamama AE, Friedman JF, Acosta LP, Bellinger DC, Langdon GC, Manalo DL, Olveda RM, Kurtis JD, McGarvey ST: Helminth Infection and Cognitive Impairment among Filipino Children. Am J Trop Med Hyg 2005, 72:540-548.

13. Nokes C, Grantham-McGregor SM, Sawyer AW, Cooper ES, Bundy DA: Parasitic helminth infection and cognitive function in school children. Proc Biol Sci 1992, 247:77-81.

14. Quihui-Cota L, Astiazarán-García H, Valencia ME, Morales-Figueroa GG, Lopez-Mata MA, Vazquez Ortiz F: Impact of Giardia intestinalis on vitamin a status in school children from northwest Mexico. Int J Vitam Nutr Res 2008, 78:51-6. doi:10.1024/0300-9831.78.2.51.

15. Getachew M, Yewhalaw D, Tafess K, Getachew Y, Zeynudin A: Anaemia and associated risk factors among pregnant women in Gilgel Gibe dam area. Southwest Ethiopia Parasit Vectors 2012, 5:296. doi:10.1186/1756-3305-5-296.

16. Gyorkos TW, Gilbert NL, Larocque R, Casapía M: Trichuris and hookworm infections associated with anaemia during pregnancy. Trop Med Int Health 2011, 16:531-7. doi:10.1111/j.1365-3156.2011.02727.x.

17. Nurdia DS, Sumarni S, Suyoko, Hakim M, Winkvist A: Impact of intestinal helminth infection on anemia and iron status during pregnancy: a community based study in Indonesia. Southeast Asian I Trop Med Public Health 2001, 32:14-22.

18. King JD, Endeshaw T, Escher E, Alemtaye G, Melaku S, Gelaye W, Worku A, Adugna M, Melak B, Teferi T, Zerihun M, Gesese D, Tadesse Z, Mosher AW, Odermatt P, Utzinger J, Marti H, Ngondi J, Hopkins DR, Emerson PM: Intestinal parasite prevalence in an area of ethiopia after implementing the SAFE strategy, enhanced outreach services, and health extension program. PLoS Negl Trop Dis 2013, 7:e2223. doi:10.1371/journal.pntd.0002223.

19. Jemaneh $L$ : Comparative prevalences of some common intestinal helminth infections in different altitudinal regions in Ethiopia. Ethiop Med J 1998, 36:1-8

20. Worku L, Damte D, Endris M, Tesfa H, Aemero M: Schistosoma mansoni infection and associated determinant factors among school children in Sanja Town, Northwest Ethiopia. J Parasitol Res 2014, article ID 792536. doi.org/10.1155/2014/792536.

21. Abossie A, Seid M: Assessment of the prevalence of intestinal parasitosis and associated risk factors among primary school children in Chencha town. Southern Ethiopia BMC Public Health 2014, 14:166. doi:10.1186/14712458-14-166.

22. Kebede A, Verweij J, Dorigo-Zetsma W, Sanders E, Messele T, van Lieshout L, Petros B, Polderman T: Overdiagnosis of amoebiasis in the absence of Entamoeba histolytica among patients presenting with diarrhoea in Wonji and Akaki, Ethiopia. Trans R Soc Trop Med Hyg 2003, 97:305-7.

23. Mengistu A, Gebre-Selassie S, Kassa T: Prevalence of intestinal parasitic infections among urban dwellers in southwest Ethiopia. Ethiop J Health Dev 2007, 21:12-17.

24. Banteyerga $\mathrm{H}$ : Ethiopia's health extension program: improving health through community involvement. MEDICC Rev 2011, 13:3.

25. Cheesbrough M: District Laboratory Practice in Tropical Countries, Part I. 2nd edition. Cambridge: Cambridge University Press; 2009:196-198.

26. USAID/ETHIOPIA: End of the Project Evaluation for the Urban Health Extension Program. Accessed 5 April 2014, Available at https://www.dropbox.com/s/ uw361vaz4ehbnuy/7608883771268514_final.pdf?n=187041813.

27. Ahmed A, Al-Mekhlafi HM, Al-Adhroey AH, Ithoi I, Abdulsalam AM, Surin J: The nutritional impacts of soil-transmitted helminths infections among Orang Asli schoolchildren in rural Malaysia. Parasites Vectors 2012, 5:119. doi:10.1186/1756-3305-5-119.

28. Nokes C, Grantham-McGregor SM, Sawyer AW, Cooper ES, Robinson BA, Bundy DA: Moderate to heavy infections of Trichuris trichiura affect cognitive function in Jamaican school children. Parasitology 1992, 104:539-547.

29. Kamau P, Aloo-Obudho P, Kabiru E, Ombacho K, Langat B, Mucheru O, Ireri L: Prevalence of intestinal parasitic infections in certified food-handlers working in food establishments in the City of Nairobi, Kenya. J Biomed Res 2012, 26:84-9. doi:10.1016/S1674-8301(12)60016-5.

30. Wegayehu T, Tsalla T, Seifu B, Teklu T: Prevalence of intestinal parasitic infections among highland and lowland dwellers in Gamo area, South Ethiopia. BMC Public Health 2013, 13:151. doi:10.1186/1471-2458-13-151.

doi:10.1186/1756-0500-7-502

Cite this article as: Jejaw et al: Status of intestinal parasitic infections among residents of Jimma Town, Ethiopia. BMC Research Notes 2014 7:502. 